\title{
Kelayakan Lembar Penugasan Terstruktur pada Materi Laju Reaksi untuk Melatihkan Literasi Sains
}



Angelina Nur Afni, Suyono*

Program Studi S1 Pendidikan Kimia, Jurusan Kimia, Fakultas Matematika dan Ilmu Pengetahuan Alam Universitas Negeri Surabaya

*Email: suyono@unesa.ac.id

DOI: https://doi.org/10.33369/pendipa.6.1.16-25

\begin{abstract}
The purpose of this research was to produce a Structured Assignment Sheet (SAS) on chemistry learning material reaction rates that are feasible for practicing Scientific Literacy (SL). The acronym of this learning device is SASSL-Reaction Rate. The eligibility criteria include validity (construct and content), practicality, and effectiveness. The development of the SASSL-Reaction Rate uses the Research and Development $(R \& D)$ method with the following stages: (1) potential and problems; (2) data collection; (3) product design; (4) design validation; (5) design revision; (6) product testing; (7) product revision; (8) trial use; (9) product revision; and (10) mass production. This research was conducted only up to the seventh step, namely the revision of the post-trial product. The Draft SASSL-Reaction Rate that have been designed and developed are reviewed and then tested for validity through expert judgment involving three experts in the field of chemistry education. SASSL-Reaction Rate that have been declared valid are then tested on user students to evaluate their practicality and effectiveness. The criteria for the practicality of this learning device were evaluated based on the response data provided by user students. The effectiveness criteria of SASSL-Reaction Rate are based on students's test scores in scientific literacy after testing the device (One-Shot Case Study). All data were analyzed descriptively. SASSL-Reaction Rate is declared to meet the validity criteria if the value of Mo $\geq 4$ for each question and $R \geq 75 \%$. SASSLReaction Rate is declared to meet the criteria for practicality if the value of $M o \geq 3$ for each question and $R \geq 75 \%$. SASSL-Reaction Rate is declared to meet the effectiveness criteria if the percentage of students who pass is $\geq 51 \%$. The results of the research: (1) SASSL-Reaction Rate developed was declared to have meet the eligibility requirements in terms of both construct and content validity criteria, (2) SASSLReaction Rate developed was declared to have meet the eligibility requirements in terms of practicality criteria, and (3) SASSL-The reaction rate developed is declared to have met the eligibility requirements in terms of the effectiveness criteria. Thus it can be concluded that the SASSL-Reaction Rate developed is declared feasible to be used to teach scientific literacy to XI grade senior high school students.
\end{abstract}

Keywords: Reaction Rate; Structured Assignment Sheet; Scientific Literacy; One-Shot Case Study; Norms Reference Assessment.

\begin{abstract}
ABSTRAK
Tujuan penelitian ini adalah untuk mengembangkan Lembar Penugasan Terstruktur (LPT) pada pembelajaran kimia materi laju reaksi yang layak untuk melatihkan Literasi Sains (LS). Perangkat pembelajaran (learning device) ini diakronimkan dengan LPTLS-Laju Reaksi. Kriteria kelayakan meliputi validitas (konstruk dan isi), kepraktisan, dan efektivitas. Pengembangan LPTLS-Laju Reaksi menggunakan metode Research and Development (R\&D) dengan tahapan: (1) potensi dan masalah; (2) pengumpulan data; (3) desain produk; (4) validasi desain; (5) revisi desain; (6) ujicoba produk; (7) revisi produk; (8) ujicoba pemakaian; (9) revisi produk; dan (10) produksi masal. Penelitian ini dilakukan hanya sampai langkah ketujuh yaitu revisi produk pasca uji coba. Draft LPTLS-Laju reaksi yang telah dirancang dan kembangkan ditelaah dan selanjutnya diuji validitasnya melalui expert judgement melibatkan tiga ahli di bidang pendidikan kimia. LPTLS-Laju Reaksi yang telah dinyatakan valid selanjutnya diuji-coba kepada peserta didik pengguna untuk dievaluasi kepraktisan dan efektivitasnya. Kriteria kepraktisan perangkat
\end{abstract}


pembelajaran ini dievaluasi berdasar data respon yang diberikan peserta didik pengguna. Kriteria efektivitas LPTLS-Laju Reaksi didasarkan kepada skor tes peserta didik dalam literasi sains sesudah ujicoba perangkat (One-Shot Case Study). Seluruh data dianalisis secara deskriptif. LPTLS-Laju reaksi dinyatakan memenuhi kriteria kevalidan jika nilai $\mathrm{Mo} \geq 4$ untuk tiap soal dan $\mathrm{R} \geq 75 \%$. LPTLS-Laju reaksi dinyatakan memenuhi kriteria kepraktisan jika nilai $\mathrm{Mo} \geq 3$ untuk tiap soal dan $\mathrm{R} \geq 75 \%$. LPTLS-Laju reaksi dinyatakan memenuhi kriteria efektivitas jika persentase peserta didik yang lulus $\geq 51 \%$. Hasil penelitian: (1) LPTLS-Laju Reaksi yang dikembangkan dinyatakan telah memenuhi syarat kelayakan ditinjau dari kriteria validitas baik konstruksi maupun isi, (2) LPTLS-Laju Reaksi yang dikembangkan dinyatakan telah memenuhi syarat kelayakan ditinjau dari kriteria kepraktisan, dan (3) LPTLS-Laju Reaksi yang dikembangkan dinyatakan telah memenuhi syarat kelayakan ditinjau dari kriteria efektivitas. Dengan demikian dapat disimpulkan bahwa LPTLS-Laju reaksi yang dikembangkan dinyatakan layak digunakan untuk literasi sains pada peserta didik SMA kelas XI.

Kata kunci: Laju Reaksi; Lembar Penugasan Terstruktur; Literasi Sains; One-Shot Case Study; Penilaian Acuan Norma.

\section{PENDAHULUAN}

Pendidikan adalah kegiatan yang dilakukan dengan sadar dan sudah terencana yang bertujuan agar peserta didik dapat mengembangkan potensi dirinya secara aktif agar memiliki kemampuan spiritual, kecerdasan, akhlak yang mulia serta berbagai keterampilan yang berguna baik bagi dirinya maupun orang lain, bangsa, dan negara (Roesminingsih \& Susarno, 2016).

Salah satu tuntutan peserta didik abad ke-21 adalah mampu memecahkan masalah. Kegiatan belajar mengajar tidak hanya menuntut peserta didik untuk menghafalkan konsep, tetapi peserta didik juga dituntut untuk mengaplikasikan konsep yang dipahami dalam kehidupan seharihari. Hal itu disebut dengan aspek literasi sains (Suciati, 2011).

Gormally et al. (2012) menyatakan bahwa literasi sains dapat diartikan sebagai kemampuan seseorang untuk membedakan berbagai fakta sains dari bermacam-macam informasi, mengenal dan menganalisis penggunaan metode penyelidikan saintifik serta kemampuan mengorganisasi, menganalisis, dan menginterpretasikan data kuantitatif dan informasi sains. Menurut PISA (2015), literasi sains adalah kemampuan untuk menyelesaikan masalah yang berhubungan dengan sains dan pengetahuan sains. Peserta didik disebut berliterasi sains jika peserta didik mampu mengembangkan konsep-konsep sains yang diperoleh sehingga dapat meghasilkan pengetahuan baru serta mengaplikasikannya pada kehidupan sehari-hari. Kemendikbud (2017) menyatakan bahwa literasi sains membantu peserta didik untuk membentuk pola piker, perilaku dan membangun karakter peduli dan bertanggung jawab terhadap dirinya, masyarakat, alam semesta, maupun permasalahan masyarakat modern yang sangat bergantung pada kemajuan teknologi. Yuliati (2017) menyatakan bahwa dengan literasi sains, peserta didik diharapkan mampu memenuhi tuntutan pada perkembangan zaman yaitu menjadi problem solver yang berjiwa kompetitif, kreatif, inovatif,, kolaboratif, dan berkarakter. Hal tersebut disebabkan karena penguasaan kemampuan literasi sains dapat mendukung pengembangan kompetensi abad ke21.

Pembelajaran yang berbasis literasi sains dapat diterapkan dalam konsep kimia (Shwartz et al., 2006). Berdasarkan hal tersebut, literasi sains dapat dilatihkan pada peserta didik melalui pembelajaran kimia. Kimia merupakan salah satu cabang dari sains. Pemahaman konsep kimia secara komprehensif yang disertai penerapan di kehidupan sehari-hari dapat dicapai apabila peserta didik memiliki kemampuan literasi sains.

Ilmu kimia merupakan ilmu yang meliputi cara berpikir, bernalar, merumuskan masalah, melakukan percobaan dan pengamatan, menganalisis data dan menyimpulkan agar dihasilkan produk-produk sains (Hidayatin \& Mitarlis, 2018). Salah satu konsep pada pembelajaran kimia yang membutuhkan pemikiran untuk memahami aplikasi konsep tersebut dalam kehidupan sehari-hari adalah materi laju reaksi.

Salah satu masalah pendidikan di Indonesia dalam bidang sains adalah rendahnya literasi sains peserta didik (Imansari et al., 2018). Rata- 
rata skor literasi sains peserta didik Indonesia berdasarkan hasil PISA 2015 sebesar 403 poin dari rata-rata skor seluruh negara peserta yang mengikuti PISA 2015 sebesar 493 poin. Hasil tersebut memperlihatkan literasi sains yang dimiliki peserta didik Indonesia masih terletak di bawah rata-rata, bahkan Indonesia terletak di jajaran negara yang merupakan peserta PISA 2015 dengan literasi sains yang rendah yaitu pada ranking 64 dari 72 negara (OECD, 2018). Sekolah di kota yang memiliki nilai UN tinggi, literasi sains peserta didiknya tergolong rendah (Lestari et al., 2019). Literasi sains peserta didik di Aceh Lamiang berada dalam kategori rendah yaitu sebesar 40,61\% (Fitriani et al., 2018). Penelitian Fibonacci \& Sudarmin (2014) dihasilkan bahwa tingkat literasi sains yang dimiliki peserta didik pada pengetahuan kimia rendah. Penelitian Rachmatullah et al. (2016) dihasilkan bahwa tingkat literasi sains peserta didik di Smedang berada dalam kategori rendah yaitu rendah sebesar $51 \%$ dan sangat rendah sebesar 30\%. Penelitian Rusilowati et al. (2016) dihasilkan bahwa level literasi sains peserta didik di Indonesia untuk 12 tahun berpartisipasi selalu berada di ranking lima terbawah. Kemampuan literasi sains pada sebuah kelas di Solok berada di bawah rata-rata yaitu sebesar 27.94\% (Siagian et al., 2017). Pengetahuan sains pada hampir setengah dari peserta didik SMA di Indonesia (sebanyak 41\%) tergolong rendah, bahkan sebanyak $6.9 \%$ peserta didik SMA di Indonesia tidak memiliki literasi sains (Widowati et al., 2017). Hasil pra penelitian kepada peserta didik kelas XI IPA 2 di SMA Negeri 9 Pontianak menunjukkan bahwa $>70 \%$ peserta didik hanya mampu menjawab soal dengan aspek kognitif $C_{1}$. Hasil wawancara dengan peserta didik adalah peserta didik kurang dapat menganalisis soal aplikatif karena cenderung menghafalkan materi (Fitriani et al., 2013). Hasil wawancara dengan guru kimia MAN Abdva, guru kimia menyatakan bahwa hasil belajar peserta didik pada pembelajaran kimia masih rendah atau belum mencapai Kriteria Ketuntasan Minimal (KKM) karena rendahnya literasi sains peserta didik (Mazwan, 2018). Wawancara dengan guru kimia kelas XI SMA Negeri 5 Pekanbaru diperoleh hasil bahwa peserta didik kurang dapat menghubungkan konsep yang telah diperoleh dengan permasalahan atau fenomena dalam kehidupan sehari-hari khususnya bidang kimia (Fitri \& Fatisa, 2019).

Salah satu langkah untuk mengatasi rendahnya literasi sains yang dimiliki peserta didik adalah dilatihnya literasi sains pada peserta didik agar peserta didik terbiasa ketika memecahkan permasalahan atau fenomena yang ada di lingkungan sekitar dan mengapliaksikan konsep-konsep yang telah diterima. Latihan literasi sains dapat dilakukan dengan cara disediakannya lembar penugasan terstruktur yang berisi tugas-tugas untuk peserta didik yang dirancang dengan tujuan untuk meningkatkan kemampuan tertentu dari peserta didik, dalam hal ini adalah kemampuan literasi sains.

Lembar penugasan terstruktur dapat diartikan sebagai kumpulan lembar kerja yang disusun untuk membimbing peserta didik mencapai suatu tujuan dengan sedikit bantuan dari guru agar tujuan awal dapat tercapai (Kundi, 2013).

Berdasarkan masalah yang telah dijelaskan, maka diperlukan perangkat pembelajaran yang dapat membantu melatihkan literasi peserta didik. Perangkat pembelajaran tersebut dapat berupa lembar penugasan terstruktur pada materi laju reaksi untuk melatihkan literasi sains. Lembar penugasan terstruktur pada penelitian ini disebut dengan Lembar Penugasan Terstruktur Literasi Sains-Laju Reaksi (LPTLS-Laju Reaksi).

Tujuan penelitian ini dihasilkan Lembar Penugasan Terstruktur (LPT) pada pembelajaran kimia materi laju reaksi yang layak untuk melatihkan Literasi Sains (LS). Perangkat pembelajaran (learning device) ini diakronimkan dengan LPTLS-Laju Reaksi. Kriteria kelayakan meliputi validitas (konstruk dan isi), kepraktisan, dan efektivitas sesuai dengan pendapat (Nieveen, 2010). Adanya LPTLS-Laju Reaksi diharapkan dapat dimanfaatkan untuk membelajarkan literasi sains pada peserta didik SMA kelas XI.

\section{METODE PENELITIAN}

\section{Waktu dan Lokasi Penelitian}

Penelitian ini dilaksanakan pada bulan Maret hingga April 2021 di SMA Negeri 21 Surabaya, SMA Negeri 13 Surabaya, dan SMA Wachid Hasyim 2 Taman.

\section{Subjek Penelitian}

Subjek dalam penelitian ini adalah beberapa peserta didik kelas XI dari SMA Negeri 21 
Surabaya, SMA Negeri 13 Surabaya, dan SMA Wachid Hasyim 2 Taman dengan total 15 peserta didik.

\section{Rancangan Penelitian}

Metode penelitian yang digunakan adalah metode Research and Development (R\&D). Sugiyono (2016) menyatakan bahwa metode penelitian $R \& D$ adalah metode penelitian yang bertujuan untuk menghasilkan suatu produk yang kemudian diuji efektivitasnya. Langkah-langkah metode penelitian $R \& D$ adalah sebagai berikut: (1) potensi dan masalah; (2) pengumpulan data; (3) desain produk; (4) validasi desain; (5) revisi desain; (6) ujicoba produk; (7) revisi produk; (8) ujicoba pemakaian; (9) revisi produk; dan (10) produksi masal. Penelitian ini dilakukan hanya sampai langkah ketujuh yaitu revisi produk pasca ujicoba pemakaian. Draft LPTLS-Laju Reaksi yang telah dirancang dan kembangkan ditelaah dan selanjutnya diuji validitasya melalui expert judgement melibatkan tiga ahli di bidang pendidikan kimia. LPTLS-Laju Reaksi yang telah dinyatakan valid selanjutnya diuji-coba kepada peserta didik pengguna untuk dievaluasi kepraktisan dan efektivitasnya. Kriteria kepraktisan perangkat pembelajaran ini dievaluasi berdasar data respon yang diberikan peserta didik pengguna. Kriteria efektivitas LPTLS-Laju Reaksi didasarkan kepada skor tes peserta didik dalam literasi sains sesudah ujicoba perangkat (One-Shot Case Study) sebagai berikut:

Keterangan:

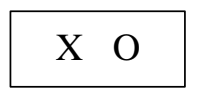

$\mathrm{X}=$ Perlakuan yang diberikan

$\mathrm{O}=$ Observasi

Model tersebut bermakna bahwa ada sebuah kelompok yang diberikan perlakuan kemudian diobservasi hasilnya (Sugiyono, 2016).

Teknik Pengumpulan Data

Penelitian ini menghasilkan data kuantitatif yang meliputi validitas (isi dan konstruk), kepraktisan, dan efektivitas. Data validitas diperoleh dengan cara pengisian lembar validasi oleh tiga validator (Dua validator merupakan dosen jurusan kimia, FMIPA, Unesa dan satu validator lainnya merupakan guru kimia di SMA Negeri 13 Surabaya).
Data kepraktisan diperoleh melalui pengisian lembar angket respon oleh peserta didik yang merupakan subjek penelitian. Lembar angket respon terdiri dari respon tertutup dan respon terbuka.

Data efektivitas diperoleh dengan pengisian lembar tes literasi sains peserta didik yang berisi pertanyaan yang disusun berdasarkan indikator literasi sains pada materi laju reaksi.

Pegembangan Instrumen

Instrumen yang digunakan pada penelitian ini adalah lembar telaah, lembar validasi (konstruk dan isi), lembar angket respon peserta didik (tertutup dan terbuka), dan lembar tes literasi sains peserta didik.

\section{Teknik Analisa Data}

Data hasil validasi dianalisis dengan metode deskriptif kuantitatif menggunakan skala Likert pada tabel berikut:

Tabel 1. Skala Likert

\begin{tabular}{c|c}
\hline Skor & Kategori Penilaian \\
\hline 5 & Sangat valid \\
\hline 4 & Valid \\
\hline 3 & Cukup valid \\
\hline 2 & Kurang valid \\
\hline 1 & Tidak valid \\
\hline
\end{tabular}

(Riduwan, 2013)

Data validitas (konstruk dan isi) dianalisis secara deskriptif kuantitatif dengan menggunakan skor yang sering muncul (Mo) yang diperoleh dari expert judgement. Skor validasi didapatkan dari tiga validator sehingga perlu adanya perhitungan kesepahaman ketiga skor yang diperoleh. Kesepahaman tersebut dapat diperoleh dengan percentage of agreement (R) sebagai berikut:

$$
R=\left[1-\frac{A-B}{A+B}\right] \times 100 \%
$$

A dan B adalah skor dari validator (A adalah skor yang lebih tinggi dan B adalah skor paling rendah). Skor validasi didapatkan dari tiga validator sehingga masing-masing $\mathrm{R}$ dihitung persentasenya, yaitu $(\mathrm{R})_{1,2} ;(\mathrm{R})_{1,3}$; dan $(\mathrm{R})_{2,3}$. Validitas konstruk dan isi dinyatakan realiabel jika $\mathrm{R} \geq 75 \%$ (Borich, 1994). LPTLS-Laju Reaksi dinyatakan memenuhi syarat validitas konstruk dan isi jika setiap pertanyaan memiliki Mo minimal 4 dan tidak ditemukan ketidaksepahaman antar validator. 
Data kepraktisan diperoleh dengan pengisian lembar angket respon oleh peserta didik. Hasil pengisian lembar angket respon tersebut berupa skor yang dihitung menggunakan skala Likert yang tertera pada Tabel 2.

Tabel 2. Skala Likert Lembar Angket Respon

\begin{tabular}{c|c}
\hline Penilaian & Skor \\
\hline Sangat tidak setuju & 1 \\
\hline Tidak setuju & 2 \\
\hline Setuju & 3 \\
\hline Sangat setuju & 4 \\
\hline
\end{tabular}

(Sugiyono, 2016)

Skor yang diperoleh kemudian diinterpretasikan dengan kriteria persentase kepraktisan yang tertera pada Tabel 3 .

Tabel 3. Kriteria Persentase Kepraktisan

\begin{tabular}{c|c}
\hline Skor & Kategori Penilaian \\
\hline 4 & Sangat praktis \\
\hline 3 & Praktis \\
\hline 2 & Kurang praktis \\
\hline 1 & Tidak Praktis \\
\hline
\end{tabular}

(Riduwan, 2013)

Data kepraktisan dianalisis secara deskriptif kuantitatif. Analisis deskriptif kuantitatif menggunakan skor yang sering muncul (Mo) pada setiap soal. Mo yang diperoleh diinterpretasikan pada kategori penilaian yang terdapat pada Tabel 3 dan juga dilakukan perhitungan nilai $\mathrm{R}$ untuk setiap peserta didik.

Data efektivitas yang telah diperoleh berdasarkan perhitungan nilai hasil pengerjaan lembar tes literasi sains peserta didik dianalisis menggunakan metode Penilaian Acuan Norma (PAN) dan menggunakan konversi skala lima. Kemudian nilai yang diperoleh peserta didik diinterpretasikan berdasarkan kategori nilai yang telah dibuat dengan konversi skala lima. Selanjutnya, ditetapkan peserta didik yang lulus atau remidi kemudian dihitung persentase banyaknya peserta didik yang lulus dan persentase banyaknya peserta didik yang remidi. Setelah itu, persentase tersebut diinterpretasikan pada konversi kelulusan peserta didik yang tertera pada Tabel 4.

Tabel 4. Kriteria Persentase Efektivitas

\begin{tabular}{c|c}
\hline Persentase (\%) & Kriteria \\
\hline $0-20$ & Tidak efektif \\
\hline $21-50$ & Kurang efektif \\
\hline $51-75$ & Efektif \\
\hline
\end{tabular}

\begin{tabular}{c|c}
\hline $76-100$ & Sangat efektif \\
\hline \multicolumn{2}{|c}{ (Arikunto, 2010) }
\end{tabular}

\section{HASIL DAN PEMBAHASAN}

Lembar penugasan terstruktur dapat diartikan sebagai kumpulan lembar kerja yang disusun untuk membimbing peserta didik mencapai suatu tujuan dengan sedikit bantuan dari guru agar tujuan awal dapat tercapai (Kundi, 2013).

Lembar Penugasan Terstruktur sebagai perangkat yang di dalamnya memuat tahapantahapan untuk mencapai tujuan tertentu. Lembar Penugasan Terstruktur pada penelitian ini adalah Lembar Penugasan Terstruktur Literasi SainsLaju Reaksi (LPTLS-Laju Reaksi) dimana LPTLS-Laju Reaksi bertujuan untuk melatihkan literasi sains pada materi laju reaksi.

Literasi sains yang dilatihkan pada peserta didik melalui LPTLS-Laju Reaksi telah disesuaikan dengan indikator literasi sains yaitu indikator keberhasilan literasi sains. Indikator literasi sains yang digunakan sebagai dasar dalam pengembangan LPTLS-Laju Reaksi mengutip dari Gormally et al. (2012); PISA (2015); dan Rizkita et al. (2016) dinyatakan pada Tabel 5.

\begin{tabular}{|c|c|}
\hline No & Indikator \\
\hline 1 & $\begin{array}{l}\text { Mengidentifikasi pendapat ilmiah dengan } \\
\text { benar }\end{array}$ \\
\hline 2 & Melakukan studi literatur yang efektif \\
\hline 3 & Memahami desain penelitian \\
\hline 4 & Membuat grafik sesuai data dengan tepat \\
\hline 5 & $\begin{array}{l}\text { Memecahkan masalah dengan } \\
\text { memanfaatkan keterampilan } \\
\text { termasuk statistik dasar }\end{array}$ \\
\hline 6 & $\begin{array}{l}\text { Memahami dan menginterpretasikan } \\
\text { statistik dasar }\end{array}$ \\
\hline 7 & $\begin{array}{l}\text { Melakukan inferensi, prediksi, dan } \\
\text { penarikan simpulan ditinjau dari data } \\
\text { kuantitatif }\end{array}$ \\
\hline \multicolumn{2}{|c|}{$\begin{array}{l}\text { Sebelum diimplementasikan dalam } \\
\text { pembelajaran kimia, LPTLS-Laju Reaksi yang } \\
\text { dikembangkan perlu dilakukan uji kelayakan. } \\
\text { Kriteria kelayakan meliputi validitas (konstruk } \\
\text { dan isi), kepraktisan dan efektivitas sesuai } \\
\text { pernyataan Nieveen (2010) bahwa uji kelayakan } \\
\text { terdiri atas tiga aspek yaitu validitas (isi dan } \\
\text { konstruk), kepraktisan, dan efektivitas. Sebelum }\end{array}$} \\
\hline
\end{tabular}


dilakukan uji kelayakan, LPTLS-Laju Reaksi yang dikembangkan ditelaah terlebih dahulu oleh dosen jurusan kimia, FMIPA, Unesa. Hasil dari telaah berupa saran dan masukan untuk perbaikan LPTLS-Laju Reaksi sebelum dilakukan uji kelayakan.

\section{Uji Kelayakan Berdasarkan Validitas}

Salah satu kriteria kelayakan sesuai dengan pendapat Nieveen (2010) adalah validitas (konstruk dan isi). Menurut Sugiyono (2016), validitas harus memenuhi validitas isi (content validity) dan validitas konstruk (construct validity) yang didukung oleh Nieveen (2007) bahwa indikator validitas mencakup konsistensi (validitas konstruk) dan relevansi (validitas isi).

Uji validitas dilakukan melalui expert judgement melibatkan tiga ahli di bidang pendidikan kimia. Data validitas diperoleh dengan cara pengisian lembar validasi oleh tiga validator. Dua validator merupakan dosen jurusan kimia, FMIPA, Unesa dan satu validator lainnya adalah guru kimia di SMA Negeri 13 Surabaya. Skor yang diberikan oleh validator pada aspek kesesuaian antara substansi pertanyaan soal dengan indikator literasi sains pada Tabel 5.

Tabel 6. PenilaianValidator terhadap Konstruk LPTLS-Laju Reaksi dariAspek Kesesuaian antara Substansi Pertanyaan Soal dengan Indikator Literasi Sains

\begin{tabular}{cccccc}
\multirow{2}{*}{$\begin{array}{c}\text { No } \\
\text { Soal }\end{array}$} & \multicolumn{3}{c}{ Skor } & Mo & Kategori \\
\cline { 2 - 5 } & $\mathbf{V}_{\mathbf{1}}$ & $\mathbf{V}_{\mathbf{2}}$ & $\mathbf{V}_{\mathbf{3}}$ & & \\
\hline 1 & 4 & 5 & 5 & 5 & Sangat valid \\
\hline 2 & 5 & 5 & 5 & 5 & Sangat valid \\
\hline 3 & 5 & 5 & 5 & 5 & Sangat valid \\
\hline 4 & 5 & 5 & 4 & 5 & Sangat valid \\
\hline 5 & 5 & 5 & 5 & 5 & Sangat valid \\
\hline 6 & 5 & 5 & 5 & 5 & Valid \\
\hline 7 & 5 & 4 & 4 & 4 & Valid \\
\hline 8 & 5 & 5 & 5 & 5 & Valid \\
\hline 9 & 5 & 5 & 4 & 5 & Sangat valid \\
\hline 10 & 5 & 5 & 4 & 5 & Valid \\
\hline 11 & 5 & 5 & 5 & 5 & Sangat valid \\
\hline 12 & 5 & 5 & 5 & 5 & Sangat valid \\
\hline 13 & 5 & 5 & 5 & 5 & Sangat valid \\
\hline
\end{tabular}

Berdasarkan Tabel 6 dapat dilihat bahwa modus dari ketiga validator pada soal nomor 6,7 , 8, dan 10 sebesar 4 (kategori valid). Soal lain yaitu nomor $1,2,3,4,5,9,11,12$, dan 13 keseluruhan memperoleh nilai modus sebesar 5 (kategori sangat valid). Berdasarkan hal tersebut dapat dinyatakan bahwa LPTLS-Laju Reaksi telah memenuhi syarat ditinjau dari validitas konstruk.

Skor validasi diperoleh dari tiga validator sehingga masing-masing $\mathrm{R}$ dihitung persentasenya, yaitu $(\mathrm{R})_{1,2} ;(\mathrm{R})_{1,3} ;$ dan $(\mathrm{R})_{2,3}$. Berikut adalah hasil perhitungan kesepahaman atau percentage of agreement $(\mathrm{R})$ :

Tabel 7. Rekapitulasi Kesepahaman Skor Validasi Konstruk

\begin{tabular}{ccccccc}
\hline \multirow{2}{*}{$\begin{array}{c}\text { No } \\
\text { Soal }\end{array}$} & & Skor & \multicolumn{4}{c}{$\begin{array}{c}\text { Percentage of } \\
\text { Agreement } \\
(\mathbf{R})\end{array}$} \\
\cline { 2 - 7 }$(\mathbf{\%})$
\end{tabular}

Berdasarkan Tabel 7 dapat dilihat bahwa persentase kesepahaman seluruh validator berada pada rentang $89 \%$ - $100 \%$ yang berarti skor ketiga validator tidak ada perbedaan yang signifikan sehingga dapat dinyatakan bahwa LPTLS-Laju Reaksi memenuhi syarat ditinjau dari validitas konstruk.

Penilaian validitas isi juga dilakukan melalui expert judgement. Skor hasil validitas isi tertera pada Tabel 8.

Tabel 8. Hasil terkait Validitas Isi LPTLS-Laju Reaksi

\begin{tabular}{cccccc}
\hline \multirow{2}{*}{$\begin{array}{c}\text { No } \\
\text { Soal }\end{array}$} & \multicolumn{3}{c}{ Skor } & \multirow{2}{*}{ Mo } & Kategori \\
\cline { 2 - 5 } & $\mathbf{V}_{\mathbf{1}}$ & $\mathbf{V}_{\mathbf{2}}$ & $\mathbf{V}_{\mathbf{3}}$ & & \\
\hline 1 & 5 & 5 & 5 & 5 & Sangat valid \\
\hline 2 & 5 & 5 & 5 & 5 & Sangat valid \\
\hline 3 & 5 & 5 & 5 & 5 & Sangat valid \\
\hline
\end{tabular}

Berdasarkan Tabel 8 dapat dilihat bahwa keseluruhan soal mendapatkan nilai modus dari ketiga validator sebesar 5 (kategori sangat valid). 
Berdasarkan hal tersebut dapat dinyatakan bahwa LPTLS-Laju Reaksi telah memenuhi syarat ditinjau dari validitas isi.

Skor validasi diperoleh dari tiga validator sehingga masing-masing $\mathrm{R}$ dihitung persentasenya, yaitu $(\mathrm{R})_{1,2} ;(\mathrm{R})_{1,3}$; dan $(\mathrm{R})_{2,3}$. Berikut adalah hasil perhitungan kesepahaman atau percentage of agreement $(\mathrm{R})$ :

Tabel 9. Rekapitulasi Kesepahaman Skor Validasi Isi

\begin{tabular}{|c|c|c|c|c|c|c|}
\hline \multirow[t]{2}{*}{$\begin{array}{c}\text { No } \\
\text { Soal }\end{array}$} & \multicolumn{3}{|c|}{ Skor } & \multicolumn{3}{|c|}{$\begin{array}{c}\text { Percentage of } \\
\text { Agreement (R) } \\
(\%)\end{array}$} \\
\hline & $V_{1}$ & $V_{2}$ & $\mathbf{V}_{\mathbf{3}}$ & $\mathbf{R}_{1,2}$ & $\mathbf{R}_{1,3}$ & $\mathbf{R}_{2,3}$ \\
\hline 1 & 5 & 5 & 5 & 100 & 100 & 100 \\
\hline 2 & 5 & 5 & 5 & 100 & 100 & 100 \\
\hline 3 & 5 & 5 & 5 & 100 & 100 & 100 \\
\hline
\end{tabular}

Berdasarkan Tabel 9 dapat dilihat bahwa keseluruhan persentase kesepahaman yang diberikan ketiga validator sebesar $100 \%$ yang menunjukkan bahwa skor ketiga validator tidak ada perbedaan yang signifikan sehingga dapat dinyatakan bahwa LPTLS-Laju Reaksi memenuhi syarat ditinjau dari validitas isi.

\section{Uji Kelayakan Berdasarkan Kepraktisan}

Data kepraktisan LPTLS-Laju Reaksi diperoleh berdasarkan hasil pengisian lembar angket oleh peserta didik (tertutup dan terbuka). Angket respon terbuka bertujuan untuk melengkapi angket respon tertutup sehingga dapat diketahui hal-hal yang tidak dijelaskan dalam pengisian angket tertutup. Berikut adalah rekapitulasi hasil angket respon tertutup:

Tabel 10. Rekapitulasi Lembar Angket Respon Tertutup

\begin{tabular}{cccccc}
\hline $\begin{array}{c}\text { No } \\
\text { Soal }\end{array}$ & Mo & Kategori & $\begin{array}{c}\text { No } \\
\text { Soal }\end{array}$ & Mo & Kategori \\
\hline 1 & 3 & Praktis & 8 & 3 & Praktis \\
\hline 2 & 3 & Praktis & 9 & 3 & Praktis \\
\hline 3 & 3 & Praktis & 10 & 3 & Praktis \\
\hline 4 & 3 & Praktis & 11 & 3 & Praktis \\
\hline 5 & 3 & Praktis & 12 & 3 & Praktis \\
\hline 6 & 3 & Praktis & 13 & 3 & Praktis \\
\hline 7 & 3 & Praktis & & & \\
\hline
\end{tabular}

Berdasarkan Tabel 10, dapat dilihat bahwa keseluruhan soal mendapatkan nilai modus dari seluruh peserta didik pengguna sebesar 3 dengan kategori praktis. Skor angket respon diperoleh dari lima belas peserta didik pengguna sehingga masing-masing $\mathrm{R}$ dihitung persentasenya. Perhitungan $\mathrm{R}$ diperoleh hasil bahwa persentase kesepahaman yang diberikan seluruh peserta didik pengguna sebanyak $97 \%$ terdapat pada daerah $\geq 75 \%$ dan terdapat persentase yang berada di daerah $<75 \%$ yaitu sebanyak $3 \%$ yang berarti skor pemberian peserta didik pengguna ada perbedaan yang sedikit signifikan. Berdasarkan hal tersebut dapat dinyatakan bahwa LPTLS-Laju Reaksi telah memenuhi syarat kepraktisan.

Angket terbuka digunakan untuk menunjukkan keselarasan respon peserta didik yang terdapat pada angket tertutup. Peserta didik menilai bahwa LPTLS-Laju Reaksi yang dikembangkan sudah praktis untuk melatihkan literasi sains. Pendapat tersebut diperkuat dengan respon peserta didik yang menyatakan bahwa peserta didik terfasilitasi untuk berlatih literasi sains dengan adanya LPTLS-Laju Reaksi. Hal tersebut menunjukkan bahwa LPTLS-Laju Reaksi yang dikembangkan telah memenuhi kriteria kepraktisan.

\section{Uji Kelayakan Berdasarkan Efektivitas}

Efektivitas LPTLS-Laju Reaksi dinilai berdasarkan hasil pengisian lembar tes literasi sains oleh peserta didik. Lembar tes literasi sains berisi pertanyaan yang disusun berdasarkan indikator literasi sains pada materi laju reaksi. Data yang diperoleh kemudian dianalisis menggunakan metode PAN.

Dasar penilaian pada PAN adalah kurva normal. Besaran yang digunakan untuk menginterpretasikan nilai yang didapatkan peserta didik adalah rata-rata (mean) dan standar deviasi (Ali \& Khaeruddin, 2012). Metode PAN membandingkan nilai antar peserta didik dalam kelompok/kelasnya (Arifin, 2009; Sukardi, 2008; Hidayatin \& Mitarlis, 2018).

PAN bersifat sangat relatif karena dapat bergeser ke kanan ataupun ke kiri pada kurva normal. Pergeseran itu dipengaruhi oleh nilai rata-rata (mean) dan nilai standar deviasi yang diperoleh pada kurva normal tersebut (Ali \& Khaeruddin, 2012).

Nilai pada metode PAN memiliki sifat relatif yang artinya jika sudah menyusun pedoman konversi nilai berdasarkan tes yang telah dilakukan pada suatu kelompok ataupun 
kelas, maka pedoman konversi tersebut hanya berlaku untuk kelompok atau kelas itu, tidak berlaku untuk kelompok atau kelas lain karena distribusi nilai peserta didik sudah berbeda (Afandi, 2013).

Berdasarkan hasil penilaian lembar tes literasi sains, berikut hasilnya:

Tabel 11. Rekapitulasi Hasil Tes Literasi Sains

\begin{tabular}{|c|c|c|c|c|c|}
\hline No & Nama & Skor & No & Nama & Skor \\
\hline 1 & AQ & 92 & 9 & $\mathrm{AL}$ & 28 \\
\hline 2 & $\mathrm{NO}$ & 87 & 10 & $\mathrm{CH}$ & 24 \\
\hline 3 & $\mathrm{PU}$ & 84 & 11 & $\mathrm{CA}$ & 23 \\
\hline 4 & SA & 60 & 12 & HA & 21 \\
\hline 5 & AN & 53 & 13 & $\mathrm{AZ}$ & 18 \\
\hline 6 & $\mathrm{AU}$ & 37 & 14 & FR & 12 \\
\hline 7 & $\mathrm{JI}$ & 33 & 15 & $\mathrm{AV}$ & 1 \\
\hline 8 & FI & 30 & & & \\
\hline & $\mathrm{M}$ & & & 40.2 & \\
\hline & SD & & & 28.55 & \\
\hline
\end{tabular}

Hasil yang diperoleh kemudian dilakukan penyusuman pedoman konversi nilai menggunakan konversi skala lima dengan perhitungan sebagai berikut:

$$
\begin{aligned}
& M+1.5(S D) \rightarrow 40.2+1.5(28.55)=83 \\
& M+0.5(S D) \rightarrow 40.2+0.5(28.55)=54 \\
& M-0.5(S D) \rightarrow 40.2-0.5(28.55)=26 \\
& M-1.5(S D) \rightarrow 40.2-1.5(28.55)=-3
\end{aligned}
$$

Berikut adalah pedoman konversi nilai yang telah disusun berdasarkan perhitungan yang telah dilakukan:

Tabel 12. Pedoman Konversi Nilai

\begin{tabular}{c|c}
\hline Nilai & Kategori Nilai \\
\hline $83-100$ & $\mathrm{~A}$ \\
\hline $54-82$ & $\mathrm{~B}$ \\
\hline $26-53$ & $\mathrm{C}$ \\
\hline$-3-25$ & $\mathrm{D}$ \\
\hline$<-2$ & $\mathrm{E}$ \\
\hline
\end{tabular}

Konversi nilai pada Tabel 12 terdapat nilai yang eror. Nilai minium yang diperoleh peserta didik sebesar nol, tetapi pada pedoman konversi tersebut terdapat rentang nilai $\leq-3$. Hal tersebut disebabkan oleh jangkauan data yang terlalu besar yaitu sebesar 91, dengan skor tertinggi sebesar 92 dan skor terendah sebesar 1 yang menyebabkan nilai standar deviasi cukup besar pula yaitu 28.55 dan didukung dengan nilai $\mathrm{M}$ yang rendah yaitu hanya sebesar 40.2 sehingga ketika penyusunan pedoman konversi nilai dihasilkan hasil yang tidak sesuai yaitu rentang data yang bernilai negatif. Pedoman konversi nilai yang tidak sesuai tetap dapat digunakan karena hal tersebut diperoleh berdasarkan distribusi nilai pada suatu kelas dan sesuai dengan pendapat Ali \& Khaeruddin (2012) yang menyatakan bahwa PAN bersifat sangat relatif karena dapat bergeser ke kanan ataupun ke kiri pada kurva normal. Pergeseran itu dipengaruhi oleh nilai rata-rata (mean) dan nilai standar deviasi yang diperoleh pada kurva normal tersebut.

Nilai yang diperoleh pserta didik dengan pengisian lembar tes literasi sains peserta didik kemudian dikonversikan ke dalam kategori nilai sesuai dengan pedoman konversi nilai yang telah disusun pada Tabel 12. Selanjutnya, peserta didik dengan kategori nilai $\mathrm{A}, \mathrm{B}$ dan $\mathrm{C}$ dapat dinyatakan lulus, sedangkan peserta didik dengan kategori nilai $\mathrm{D}$ dan $\mathrm{E}$ dinyatakan remidi/tidak lulus. Berikut adalah hasilnya:

Tabel 13. Rekapitulasi Hasil Interpretasi Nilai Peserta Didik terhadap Pedoman Konversi Nilai

\begin{tabular}{c|c|c|c|c}
\hline No & Nama & Nilai & $\begin{array}{c}\text { Kategori } \\
\text { Nilai }\end{array}$ & Keterangan \\
\hline 1 & AQ & 92 & A & Lulus \\
\hline 2 & NO & 87 & A & Lulus \\
\hline 3 & PU & 84 & A & Lulus \\
\hline 4 & SA & 60 & B & Lulus \\
\hline 5 & AN & 53 & C & Lulus \\
\hline 6 & AU & 37 & C & Lulus \\
\hline 7 & JI & 33 & C & Lulus \\
\hline 8 & FI & 30 & C & Lulus \\
\hline 9 & AL & 28 & C & Lulus \\
\hline 10 & CH & 24 & D & Remidi \\
\hline 11 & CA & 23 & D & Remidi \\
\hline 12 & HA & 21 & D & Remidi \\
\hline 13 & AZ & 18 & D & Remidi \\
\hline 14 & FR & 12 & D & Remidi \\
\hline 15 & AV & 1 & D & Remidi \\
\hline
\end{tabular}

Banyaknya peserta didik yang lulus dan remidi kemudian dihitung persentasenya dan diperoleh hasil bahwa sebesar $60 \%$ peserta didik lulus dan sebesar $40 \%$ peserta didik remidi. Persentase tersebut kemudian diinterpretasikan dengan konversi efektivitas berdasarkan jumlah 
peserta didik yang lulus. Konversi tersebut dpaat dilihat pada Tabel 4. Hasil yang diperoleh adalah LPTLS-Laju Reaksi dapat dinyatakan efektif.

Uji kelayakan pada LPTLS-Laju Reaksi yang meliputi validitas (isi dan konstruk), kepraktisan dan efektivitas diperoleh hasil bahwa LPTLS-Laju Reaksi telah memenuhi syarat kelayakan ditinjau dari validitas (konstruk dan isi), kepraktisan, dan efektivitas. Dengan demikian dapat disimpulkan bahwa LPTLS-Laju reaksi yang dikembangkan dinyatakan layak digunakan untuk pembelajaran literasi sains pada peserta didik SMA kelas XI.

\section{KESIMPULAN}

Simpulan yang diperoleh berdasarkan pembahasan hasil penelitian adalah sebagai berikut: (1) LPTLS-Laju Reaksi yang dikembangkan dinyatakan telah memenuhi syarat kelayakan ditinjau dari kriteria validitas baik konstruk maupun isi, (2) LPTLS-Laju Reaksi yang dikembangkan dinyatakan telah memenuhi syarat kelayakan ditinjau dari kriteria kepraktisan, dan (3) LPTLS-Laju Reaksi yang dikembangkan dinyatakan telah memenuhi syarat kelayakan ditinjau dari kriteria efektivitas. Dengan demikian dapat disimpulkan bahwa LPTLS-Laju reaksi yang dikembangkan dinyatakan layak digunakan untuk membelajarkan literasi sains pada peserta didik SMA kelas XI.

\section{DAFTAR PUSTAKA}

Afandi, M. (2013). Evaluasi Pembelajaran Sekolah Dasar. Unissula Press.

Ali, S., \& Khaeruddin. (2012). Evaluasi Pembelajaran. Badan Penerbit UNM Makassar.

Arifin, Z. (2009). Evaluasi Pembelajaran. PT. Rosdakarya.

Arikunto. (2010). Prosedur Penelitian Suatu Pendekatan Praktik. PT. Rineka Cipta.

Borich, G. (1994). Observation Skill for Effective Teaching. Mac Millan Publishing Company.

Fibonacci, A., \& Sudarmin. (2014). Development Fun-Chem Learning Materials Integrated Socio-Science Issues to Increase Students Scientific Literacy. International Jurnal of Science and Research (IJSR), 3(11), 708-713.
Fitri, I., \& Fatisa, Y. (2019). Penerapan Model Pembelajaran Inkuiri Terbimbing Untuk Mendukung Kemampuan Literasi Sains Siswa Pada Materi Sistem Koloid. Journal of Natural Science and Integration, 2(2), 181-190.

Fitriani, Harahap, F., \& Manurung, B. (2018). Biology Scientific Literacy of Indonesian Students: Case Study in Aceh Tamiang Aceh. International Journal of Reasearch and Review, 5(3), 63-72.

Fitriani, W., Hairida, \& Lestari, I. (2013). Deskripsi Literasi Sains Siswa dalam Model Inkuiri pada Materi Laju Reaksi di SMAN 9 Pontianak. Pendidikan Kimia FKIP Untan, 1-13.

Gormally, C., Brickman, P., \& Lutz, M. (2012). Developing a Test of Scientific Literacy Skills (TOSLS): Measuring Undergraduates' Evaluation of Scientific Information and Arguments. Life Sciences Education, $\quad 11, \quad 364-377$. https://doi.org/10.1187/cbe.12-03-0026.

Hidayatin, S., \& Mitarlis. (2018). Pengembangan Lembar Kegiatan Peserta Didik (LKPD) pada Materi Koloid untuk Melatihkan Keterampilan Literasi Sains. Unesa Journal of Chemical Education, 7(1), 76-80.

Imansari, M., Sudarmin, \& Sumarni, W. (2018). analisis literasi kimia peserta didik melalui pembelajaran inkuiri terbimbing bermuatan etnosains. Jurnal Inovasi Pendidikan Kimia, 12(2), 2201-2211.

Kemendikbud. (n.d.). Materi Pendukung Literasi Sains. Kementrian Pendidikan dan Kebudayaan.

Kundi, S. (2013). Pengaruh Penggunaan Lembar Kegiatan Siswa Terstruktur terhadap Hasil Belajar Fisika Siswa Kelas XI IPA SMA Negeri 1 POL-UT Kabupaten Takalar. Jurnal Pendidikan Fisika Unismuh, 1(3), 219-225.

Lestari, E., Adisyahputra, \& Komala, R. (2019). The Science Literacy Ability of Students in Junior High School Reviewed by the Science Literacy Ability of Teachers and School Geographical Location. Edusains, $11(1)$.

Mazwan. (2018). Pengaruh Model Pembelajaran Inkuiri Terbimbing dan Kemampuan Literasi Sains terhadap Hasil Belajar Siswa 
pada Materi Laju Reaksi di MAN ABDYA. Skripsi.

Nieveen, N. (2007). Formative Evaluation in Educational Design Research. Yhe East China Normal University.

Nieveen, N. (2010). Formative Evaluation in Educational Design Research. An Introduction to Educational Design Research. Proceedings of the Seminar Conducted at Shanghai (PR China).

OECD. (2018). PISA for Development Assessment ang Analytical Framework: Reading, Mathematics and Science, Preliminary Version. OECD Publishing.

PISA. (2015). Draft Science Framework. PISA OECD.

Rachmatullah, A., Diana, S., \& Rustaman, N. Y. (2016). Profile of middle school students on scientific literacy achievements by using scientific literacy assessments ( SLA ). AIP Conference Proceedings. https://doi.org/10.1063/1.4941194

Riduwan. (2016). Skala Pengukuran VariabelVariabel Penelitian. Alfabeta.

Rizkita, L., Suwono, H., \& Susilo, H. (2016). Analisis Kemampuan Awal Literasi Sains Siswa SMA Kota Malang. Prosiding Seminar Nasional II , Kerjasama Prodi Pendidikan Biologi FKIP Dengan Pusat Studi Lingkungan Dan Kependudukan (PSLK) Universitas Muhammadiyah Malang.

Roesminingsih, \& Susarno, L. H. (2016). Teori dan Praktek Pendidikan. Lembaga Pengkajian dan Pengembangan Ilmu Pendidikan, Fakultas Ilmu Pendidikan, Universitas Negeri Surabaya. https://jurnal.fkip.uns.ac.id/index.php/snps/ article/view/11400

Rusilowati, A., Kurniawati, L., \& Nugroho, S. E. (2016). Developing an Instrument of Scientific Literacy Asessment on the Cycle Theme. International Journal Of Environmental \& Science Education, 11(12), 5718-5727.
Shwartz, Y., Bez-Zvi, R., \& Hofstein, A. (2006). The use of scientific literacy taxonomy for assessing the development of chemical literacy among high-school students. Chemistry Education Research \& Practice, 7(4), 203-225.

Siagian, P., Silitonga, M., \& Djulia, E. (2017). Scientific Literacy Skills of Seventh Grade Junior High School (SMP Negeri) Students in North Labuhanbatu Regency. International Journal of Humanities Social Sciences and Education (IJHSSE), 4(11), 176-182.

Suciati, R. (2011). Identifikasi Kemampuan Siswa dalam Pembelajaran Biologi Ditinjau dari Aspek Literasi Sains. Jurnal FKIP UNS, 1(1).

Sugiyono. (2016). Metode Penelitian Kuantitaif, Kualitatif dan $R \& D$. Alfabeta.

Sukardi. (2008). Evaluasi Pendidikan Prinsip dan Operasionalnya. Bumi Aksara.

Widowati, A., Anjarsari, P., Rahardjo, S. B., Elfi, V. H., Yuliati, L., \& Munfaridah, N. (2017). The Development of Scientific Literacy through Nature of Science ( NoS ) within Inquiry Based Learning Approach The Development of Scientific Literacy through Nature of Science ( NoS ) within Inquiry Based Learning Approach. International Conference on Science and Applied Science.

Yuliati, Y. (2017). Literasi Sains dalam Pembelajaran IPA. Jurnal Cakrawala Pendas, 3(2), 21-28. 